\title{
Comparing the Effect of Dienogest and OCPS on Pain and Quality of Life in Women with Endometriosis: A Randomized, Double-Blind, Placebo-Controlled Trial
}

\author{
${ }^{1}$ Resident of obstetrics and gynecology, Iran university of Medical Sciences, Tehran, Iran \\ 2Endometriosis Research Center, Iran University of Medical Sciences, Tehran, Iran \\ ${ }^{3}$ Psychology Department, Islamic Azad University, Qaenat Branch, Qaenat, Iran
}

Gelareh Niakan, MD; Samaneh Rokhgireh, MD²; Majid Ebrahimpour, PhD; Abolfazl Mehdizadeh Kashi, MD ${ }^{2 *}$

\begin{abstract}
Background: Endometriosis is an estrogen-dependent disease that adversely affects women's quality of life (QOL). We aimed to compare the effect of dienogest and oral contraceptive pills (OCPs) on pain and QOL in women with endometriosis.

Methods: This randomized double-blind trial was conducted at Rasoul-e-Akram hospital, affiliated to Iran University of Medical Sciences, Tehran, Iran, from March 2018 to March 2020, on women with severe endometriosis confirmed by laparoscopic surgery. Ninety patients were randomly given either dienogest (Vissane $2 \mathrm{mg}$ tablet; $\mathrm{n}=30$ ), or OCPs $(\mathrm{LD} ; \mathrm{n}=30)$, or placebo $(\mathrm{n}=30)$ daily for 12 weeks. The primary objective of this study was to evaluate the patient's pain including dyspareunia, dysuria, dyschezia, and pelvic pain. The secondary outcome was considered as a change in patients' QOL score.

Results: The mean age of population was $32.99 \pm 7.1$ years. There was no significant difference in the three groups regarding baseline characteristics. Pelvic pain was significantly reduced, while the effect of medication on dysuria and dyschezia was not significant. The overall QOL score between the control and dienogest $(P=0.02)$ and OCPs groups $(P=0.001)$ was significantly different; however, the difference was not significant between the two intervention groups

Conclusion: The finding of the present study revealed that there is no difference in the efficacy of dienogest and OCPs in management of pain and the QOL. But there was a significant difference between the placebo and intervention groups.

Keywords: Dienogest, Endometriosis, OCPs, Pelvic pain, Quality of life

Cite this article as: Niakan G, Rokhgireh S, Ebrahimpour M, Mehdizadeh Kashi A. Comparing the effect of dienogest and ocps on pain and quality of life in women with endometriosis: a randomized, double-blind, placebo-controlled trial. Arch Iran Med. 2021;24(9):670-677. doi: 10.34172/aim.2021.96
\end{abstract}

Received: August 25, 2020, Accepted: April 21, 2021, ePublished: September 1, 2021

\section{Introduction}

Endometriosis is an estrogen-dependent disease that affects $10.8 \%-18.6 \%$ of women of reproductive age. The prevalence of the disease in infertile women is $20 \%$ to $50 \%$, and it can be as high as $71 \%$ to $87 \%$ in women with chronic pelvic pain. ${ }^{1}$ Although endometriosis can be completely asymptomatic, acute and chronic pelvic pain, ${ }^{2}$ dyspareunia, dyschezia, chronic fatigue, ${ }^{3,4}$ and infertility are the most common symptoms that have a significant effect on the quality of life (QOL) of patients with endometriosis. ${ }^{2}$ According to the results of studies, $60 \%-70 \%$ of women with endometriosis suffer from some disorders such as poor QOL, depression, and anxiety.,2,3

Unfortunately, due to the complexity and ambiguity of endometriosis, optimal control of symptoms, especially pain, is difficult and requires careful evaluations., ${ }^{5,6}$ Therefore, the management of endometriosis-related pain may require several treatments. ${ }^{6}$ Management of endometriosis is surgical, ${ }^{6,7}$ or medical (hormonal treatment -- combined oral contraceptive pills [OCPs], progesterone, gonadotropin-releasing hormone, antiprogesterone). ${ }^{6,8}$ The effectiveness of these treatments has been investigated, but to date, there has been no consensus on this issue. ${ }^{9}$

One of the most common treatments for endometriosis is OCPs. Despite their widespread use to manage symptoms and treat the disease, unfortunately, there are few clinical trials to confirm their effectiveness, and the evidence is largely based on observational studies. ${ }^{10}$ In particular, studies involving OCPs have had difficulties with patient compliance and sample size, and in some studies, these treatments have been compared with other treatments. ${ }^{11}$ It has been claimed that by reducing ovulation, OCPs temporarily suppress ectopic implants, and reduce the inflammation and symptoms of pain caused by endometriosis. ${ }^{10}$

Dienogest is one of the other treatments that have been recommended for the management of endometriosis compared to OCPs. Studies have shown that by reducing the size of endometriosis lesions, dienogest has been able to reduce the painful symptoms of endometriosis and subsequently leads to improvement in the QOL. ${ }^{12-14}$ Contrary to some researchers' claims that progesterone alone should be considered as the forerunner of 
endometriosis-related pain control, ${ }^{15}$ reliable guidelines suggest that OCPs should still be considered as the first line of management of dysmenorrhea and pelvic pain related to endometriosis. It has been proposed that dysmenorrhea or pelvic pain related to endometriosis do not respond to non-hormonal treatments. ${ }^{16-18}$ Therefore, due to the discrepancy of the effect each of the above treatments, this research was conducted to compare the effectiveness of dienogest and OCPs on pain and QOL in women with endometriosis.

\section{Materials and Methods \\ Study Design and Patients}

This clinical trial was a randomized, double-blind, placebo-controlled clinical trial conducted in Rasoul-eAkram hospital affiliated to Iran University of Medical Sciences, Tehran, Iran, from March 2017 to March 2020. This research was to elucidate the effect of dienogest and OCPs on pain and QOL in women with endometriosis. According to Zhong's suggestion, ${ }^{19}$ the sample size was calculated 27 patients in each group; $10 \%$ were added to compensate for the potential loss to follow-up. The ultimate predicted sample size was 30 patients in each group, with a power study of $80 \%$ and the two-sided alpha error of 0.05 .

All women with severe endometriosis confirmed by laparoscopic surgery with the following inclusion criteria were recruited in the study: (1) women aged 18-45 years; (2) body mass index (BMI) $18.5-24.9 \mathrm{~kg} / \mathrm{m}^{2}$; (3) the presence of subjective symptoms during menstruation (dysmenorrhea, dyspareunia, dysuria, dyschezia, pelvic pain); (4) no pelvic pain originating from other organs such as gastrointestinal, or genitourinary systems; (5) no use of gonadotropin analog treatment or other hormonal drugs in the last 3 months; (6) no gynecological malignancy; (7) no other gynecological disease along with endometriosis (such as non-endometrioid ovarian cyst, fibroids, etc) specified by paraclinical methods; (8) no underlying diseases such as cardiovascular, respiratory, renal, hematologic, hepatic, neurologic, or psychological disorders; (9) no contraindications to OCPs or dienogest use; (10) no plan for pregnancy in near future, and (11) patients at high risk for thrombosis were excluded from the research.

Patients were eliminated if they had another gynecological disease along with endometriosis during surgery or according to pathology, those who became pregnant, were unwilling to continue cooperation, had adverse drug reactions or hypersensitivity to a steroid hormone, or had participated in research with interventions in a common clinical procedure (Figure 1).

\section{Intervention, Randomization, and Blinding of Study Participants}

The research was performed in a double-blind method; the researcher and the outcome analyzer were blinded to the group assignment. The participants $(\mathrm{n}=90)$ were randomly assigned to three groups by a computergenerated random table block of size 6. All women with severe endometriosis confirmed by laparoscopy were visited by a gynecologist at the endometriosis clinic affiliated to the hospital 7-10 days after the procedure. All the patients were operated by one specific surgeon. An assistant who was not involved in the research was requested to prepare the coded envelopes utilizing consecutive numbers, and the researcher allocated the patients to three groups based on chance. The patients and also the gynecologist who evaluated the outcome were blinded to the group assignment by the researcher. The first group received dienogest $2 \mathrm{mg}$ tablet [Atipharmed Pharmaceutical Co.] daily for three months; the second group received OCPs (LD) [Aburaihan Pharmaceutical Co] (ethinyl estradiol $30 \mu \mathrm{g}$; levonorgestrel $0.3 \mathrm{mg}$ ) daily for three months, and the third group received placebo. Placebo agents were supplied by Exir Golesorkh Pharmaceutical Co. Ltd.

\section{Outcomes, Measurements, and Follow-up}

Before laparoscopic surgery, basic parameters of the patients such as age, gravidity, parity, the number of abortions, and infertility history were either asked from the patients or extracted from the patients' medical records.

In this study, changes in the patient's pain symptoms were defined as the major outcome. To measure this parameter, the scores of dyspareunia, dysuria, dyschezia, and pelvic pain were evaluated and compared across the three groups. The dyspareunia scores were assessed by a 10-point visual analog scale (VAS) before surgery and three months after surgery. For dysuria, dyschezia, and pelvic pain, the items were a 3-point response. Possible answers to items were "Yes", "No", and "a little". For primary outcomes, the patients were evaluated before and 3 months post-operatively. On the day before surgery, all patients of all groups were asked to fill the questionnaire for the first time, the surgery has been considered as a control variable for all participants so in present study three groups were homogeneous. Also, the side effects of the three interventions 3 months after surgery were recorded and compared across the three groups.

Secondary outcomes were considered as the change in patients' QOL score and the adverse effect of drugs. Women's QOL was measured using the Persian version of the WHO Quality of Life Questionnaire (WHOQOLBREF). This scale contains 24 items divided into 4 domains: physical health (7 items), psychological health (6 items), social relationships (3 items), and environmental health (8 items). Each item is scored on a 5-point Likert scale. The minimum and maximum scores of the scale are 0 and 120, respectively. A higher score indicates higher QOL. The QOL questionnaire was completed before surgery and at the end of follow-up investigations in the third month. 


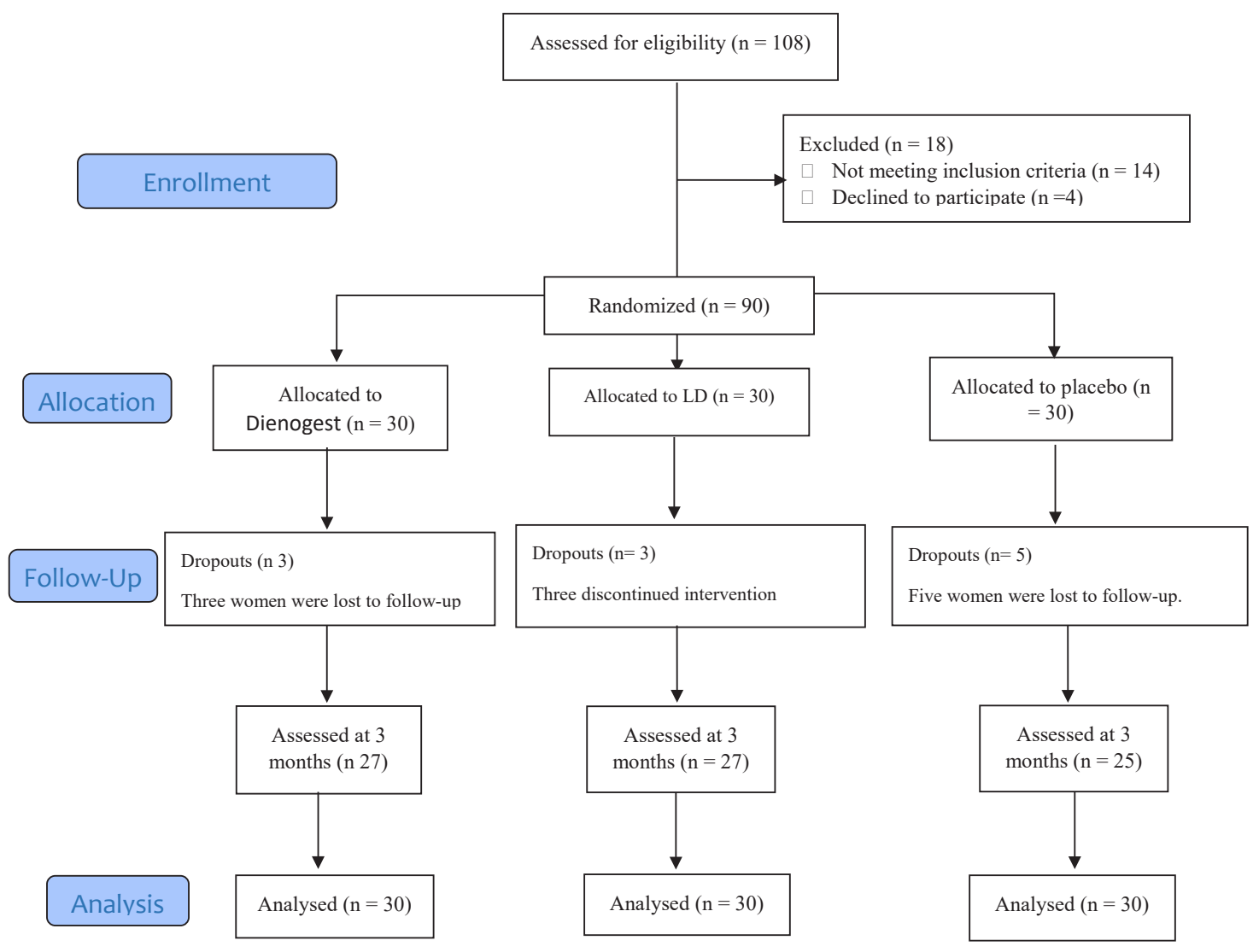

Figure 1. Diagram of the Study.

\section{Statistical Analysis}

We utilized intention-to-treat (ITT) principles and missing values were replaced by simple mean imputation. All data were transferred into the statistical software program IBM SPSS Statistics for Windows, version 21.0 (IBM Corp. 2012. Armonk, NY: IBM Corp). Qualitative variables were described by descriptive statistics and the chi-square test or Fisher's exact test was performed. The one-sample Kolmogorov-Smirnov test was used to test the normality of quantitative data, and normal probability plots were drawn for quantitative variables (Figure 2). The Levene test was utilized to test the homogeneity of variance. Analysis of covariance (ANCOVA) was used for intergroup comparison, and Tukey post hoc test was performed to designate the difference. The $P$ value was considered at 0.05 .

\section{Results}

Qualification of 108 participants was assessed, and finally, 90 were included in the study (30 patients in each group). Three, three, and five cases dropped out from the dienogest, OCPs, and placebo groups, respectively. All data from the patients were analyzed based on the ITT principle (Figure 1).

The mean age of the patients was $32.14 \pm 6.58$ years. The three groups showed no significant difference in terms of age, marital status, education, gravidity, parity, the number of abortions, the history of stillbirth, and age of onset of symptoms, disease duration, and history of infertility. The basic characteristics of the three groups are presented in Table 1.

Comparison of dyspareunia, pelvic pain, dysuria, and dyschezia between dienogest, OCPs, and placebo groups
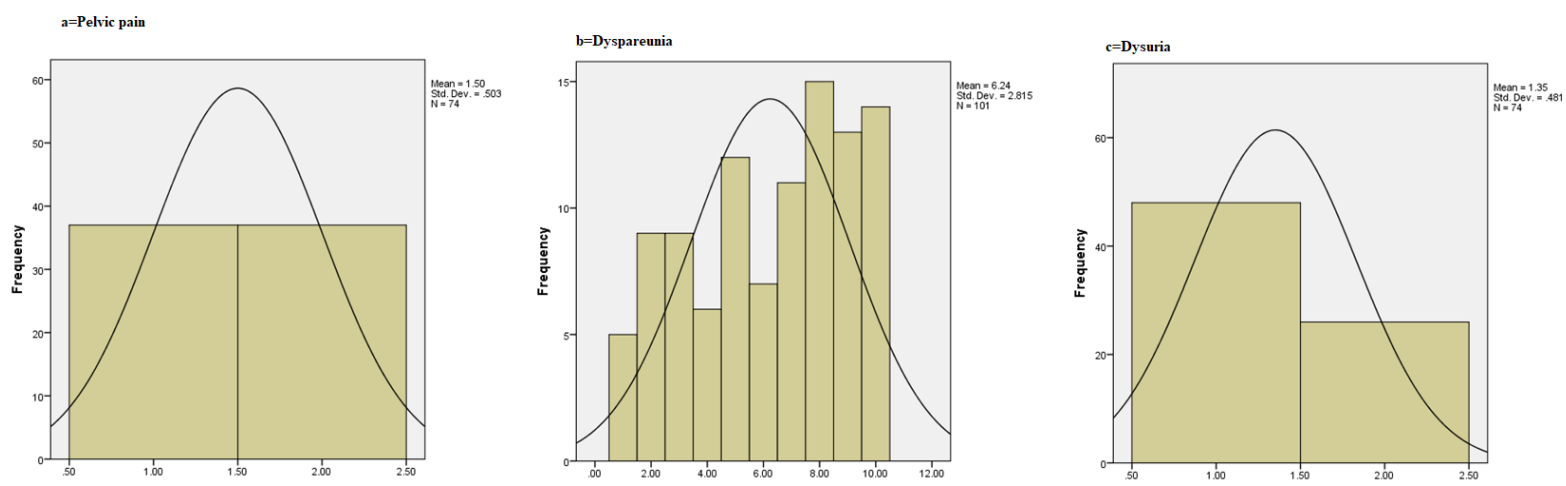

Figure 2. (a) Pelvic Pain chart; (b) Dyspareunia Chart; (c) Dysuria Chart; for the Three Groups. 
Table 1. Comparison of General Parameters Between the Groups

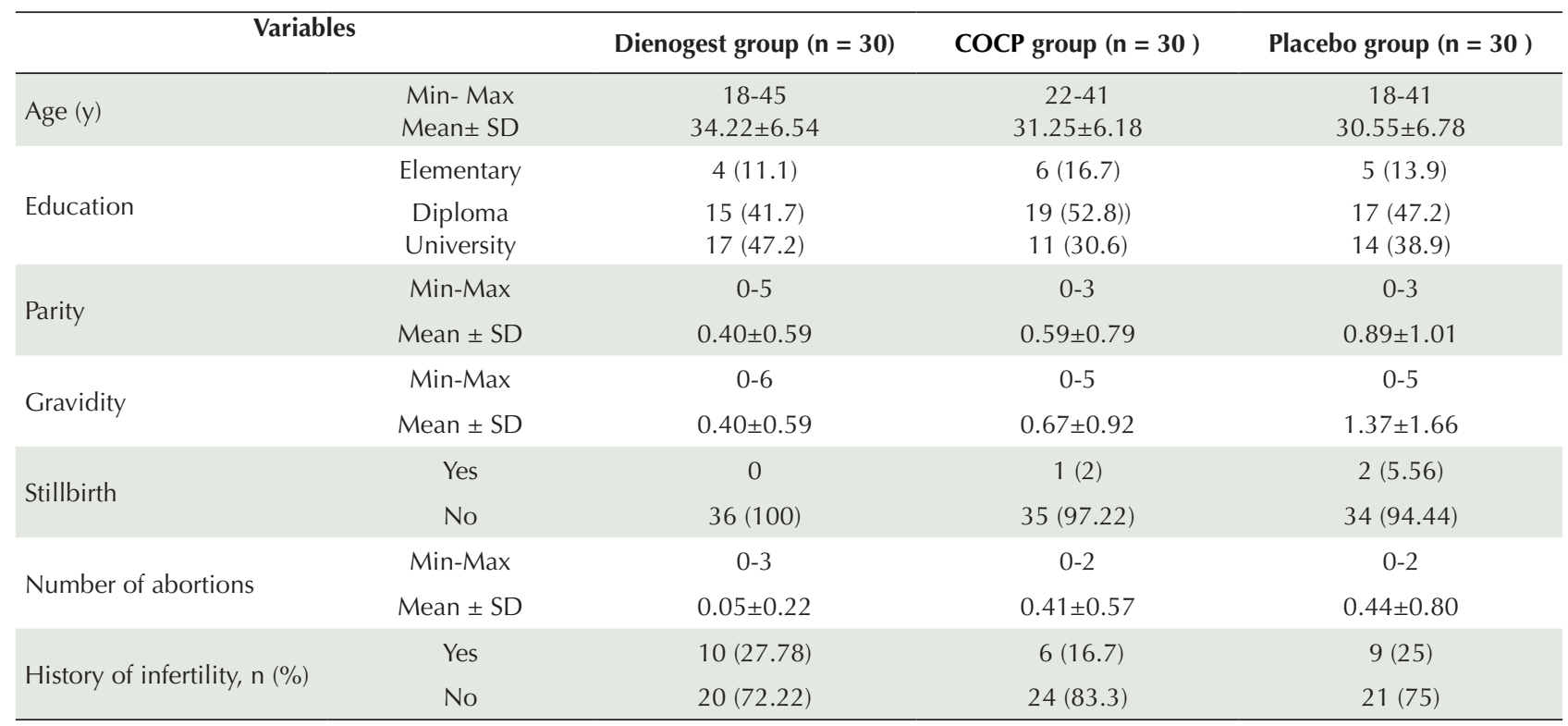

COCP, Combined oral contraceptive pill.

Table 2. Comparison of Pain Characteristics Before and After Intervention in Three Groups

\begin{tabular}{|c|c|c|c|c|c|c|c|c|c|c|c|c|c|c|c|c|c|}
\hline \multirow{2}{*}{\multicolumn{2}{|c|}{ Pain Characteristics }} & \multicolumn{5}{|c|}{ Dinogest group $(n=30)$} & \multicolumn{5}{|c|}{ COCP group $(n=30)$} & \multicolumn{6}{|c|}{ Placebo group $(n=30)$} \\
\hline & & Baseline & 3 Months & MD & $F$ & $P$ Value & Baseline & $\begin{array}{c}3 \\
\text { Months }\end{array}$ & MD & $\boldsymbol{F}$ & $\begin{array}{c}P \\
\text { Value }\end{array}$ & Baseline & $\begin{array}{c}3 \\
\text { Months }\end{array}$ & MD & $P$ Value & $P$ Value & $P$ Value \\
\hline \multicolumn{2}{|l|}{$\begin{array}{l}\text { Dyspareunia } \\
\text { Mean (SD) }\end{array}$} & $4.81 \pm 0.8$ & $\begin{array}{c}3.44 \pm \\
0.9\end{array}$ & $\begin{array}{l}0.74 \\
\pm 0.3\end{array}$ & 29.97 & $0.01^{+}$ & $\begin{array}{l}4.56 \\
\pm 1.2\end{array}$ & $\begin{array}{c}2.44 \pm \\
0.7\end{array}$ & $\begin{array}{l}2.12 \\
\pm 1.5\end{array}$ & 16.68 & $0.01^{+}$ & $4.2 \pm 1.4$ & $\begin{array}{c}3.91 \pm \\
1.3\end{array}$ & $\begin{array}{l}0.29 \\
\pm 0.4\end{array}$ & $0.65^{+}$ & $0.56^{++}$ & $0.11^{t+t+}$ \\
\hline \multirow{3}{*}{$\begin{array}{l}\text { Pelvic pain } \\
n(\%)\end{array}$} & Yes & $20(66.7)$ & $10(36.1)$ & \multirow{3}{*}{-} & & \multirow{3}{*}{$0.01^{*}$} & $20(63.9)$ & $\begin{array}{c}14 \\
(44.4)\end{array}$ & \multirow{3}{*}{-} & & \multirow{3}{*}{0.63} & $18(58.3)$ & $\begin{array}{c}15 \\
(47.2)\end{array}$ & \multirow{3}{*}{-} & \multirow{3}{*}{$0.73^{*}$} & \multirow{3}{*}{$0.617^{* *}$} & \multirow{3}{*}{$0.003^{*+1}$} \\
\hline & No & $6(22.2)$ & $20(63.9)$ & & & & $7(27.8)$ & $\begin{array}{c}15 \\
(52.8)\end{array}$ & & 0.61 & & $\begin{array}{c}11 \\
(30.56)\end{array}$ & $9(25)$ & & & & \\
\hline & A little & $4(11.1)$ & 0 & & 8.99 & & $3(8.3)$ & $1(2.8)$ & & & & $2(11.1)$ & $\begin{array}{c}(27.8) \\
6\end{array}$ & & & & \\
\hline \multirow{3}{*}{$\begin{array}{l}\text { Dysuria } \\
n(\%)\end{array}$} & Yes & $16(55.6)$ & $15(50)$ & \multirow{3}{*}{-} & & \multirow{3}{*}{$0.017^{*}$} & $14(41.7)$ & $7(25)$ & \multirow{3}{*}{-} & & & $14(44.4)$ & $\begin{array}{c}14 \\
(47.2)\end{array}$ & \multirow{3}{*}{-} & \multirow{3}{*}{$0.49^{*}$} & \multirow{3}{*}{$0.12^{* *}$} & \multirow{3}{*}{$0.81^{* * *}$} \\
\hline & No & $12(38.9)$ & $12(38.9)$ & & & & $14(41.7)$ & $\begin{array}{c}19 \\
(63.9)\end{array}$ & & 0.063 & 0.18 & $13(38.9)$ & $\begin{array}{c}16 \\
(52.8)\end{array}$ & & & & \\
\hline & A little & $2(5.6)$ & $3(11.1)$ & & 8.66 & & $2(16.7)$ & $4(11.1)$ & & & & $3(16.7)$ & 0 & & & & \\
\hline \multirow{3}{*}{$\begin{array}{l}\text { Dyschezia } \\
n(\%)\end{array}$} & Yes & 7 (30.6) & $6(22.2)$ & & & \multirow{3}{*}{0.01} & $10(33.3)$ & $6(25)$ & \multirow{3}{*}{-} & & \multirow{3}{*}{$049^{*}$} & $9(38.9)$ & $\begin{array}{c}12 \\
(27.8)\end{array}$ & \multirow{3}{*}{-} & \multirow{3}{*}{$0.7^{*}$} & \multirow{3}{*}{$0.59^{* *}$} & \multirow{3}{*}{$0.67^{* * *}$} \\
\hline & No & 21 (63.9) & $20(75)$ & & 13.74 & & $20(66.7)$ & $24(75)$ & & 0.38 & & $20(58.3)$ & $\begin{array}{c}15 \\
(63.9)\end{array}$ & & & & \\
\hline & A little & $2(5.6)$ & $4(2.8)$ & & & & 0 & 0 & & & & $1(2.8)$ & $3(8.3)$ & & & & \\
\hline
\end{tabular}

$\mathrm{MD}$, mean differences; $\mathrm{SD}$, standard deviation.

COCP, Combined oral contraceptive pill;

${ }^{+}$Comparison of before and after intervention in each group by ANOVA.

${ }^{++}$Comparison of three groups before intervention by ANOVA.

${ }^{++}$Comparison of three groups after intervention in 3 months by ANOVA.

*Comparison of before and after intervention in each group by Fisher's exact test.

${ }^{* *}$ Comparison of three groups before intervention by Fisher's exact test.

***Comparison of three groups after intervention in 3 months by Fisher's exact test.

at baseline and the third month is presented in Table 2. Dyspareunia followed the normal distribution pattern (Figure 2); therefore, ANCOVA were used for comparison. The result showed that the mean score of dyspareunia was not significantly different between the three groups. Furthermore, the frequency distribution of pelvic pain, dysuria, dyschezia was not statistically significant across the three groups before the intervention.
According to the results of ANCOVA, dyspareunia scores were not significantly different in the three groups. The mean score difference of dyspareunia pre- and post-intervention was 0.74 and 2.12 points, respectively, in the dienogest and OCPs groups. This difference was 0.29 points in the placebo group. ANCOVA revealed that although the 12-week administration of dienogest and OCPs mitigated the score of dyspareunia in the two 
intervention groups compared to placebo, this difference was not significant between the two groups $(P=0.11)$ (Table 2).

Pelvic pain was significantly reduced at 3 months after dienogest. We observed that $41.7 \%, 25 \%$, and $5.56 \%$ of patients reported improvements in pain following dienogest, OCPs, and placebo consumption. The effect of dienogest and OCPs on dysuria and dyschezia was not significant.

Based on the results of ANOVA, we observed that there was not a significant difference in the four subscales of QOL in the three groups. The mean difference between on the overall QOL score before and after the intervention was 11.55 and 15.85 points in the dienogest and OCPs groups, respectively, whereas this difference was only 5.8 points in the placebo group. The results of ANOVA indicated that this difference was significant $(P<0.003)$ (Table 3). As for the finding of the post hoc test regarding the total QOL score, there was a significant difference between the control and dienogest $(P=0.02)$ and OCPs groups $(P=0.001)$; however, there was no significant difference between the two intervention groups. The overall QOL score and the physical health, psychological health, social relationships, and environmental health subscales scores before and after the intervention are summarized in Table 3.

As the secondary outcome of the study, the 12-week administration of dienogest and OCPs had a low rate of adverse effects on women. This adverse effect did not cause women to discontinue the medication except in two patients (Table 4). So, the compliance rate with the assigned treatment was about $97 \%$. The most common complications in both groups were hair loss, headache, hot flashes, or nausea, which were $27.8 \%$ in the dienogest group and $16.7 \%$ in the OCPs group. Furthermore, spotting was more frequent in the dienogest group (6 of 36). Forty-four percent and 55.6\% of women who received dienogest and OCPs reported no complications or side effects.

\section{Discussion}

Pain is the most common symptom of endometriosis. About $75 \%$ of symptomatic patients experience some degree of dysmenorrhea and pelvic pain. Therefore, to eradicate residual lesions, and reduce recurrence and pain, various medical treatments have been suggested after laparoscopic surgery. ${ }^{20}$ In this study, we evaluated the efficacy and safety of short-term treatment with dienogest

Table 3. Comparison of Mean Quality of Life Score Before and After Intervention in Three Groups

\begin{tabular}{|c|c|c|c|c|c|c|c|c|c|c|c|c|c|c|}
\hline \multirow{2}{*}{ Quality of Life } & \multicolumn{4}{|c|}{$\begin{array}{c}\text { Dinogest group }(n=30) \\
\text { Mean }(S D)\end{array}$} & \multicolumn{4}{|c|}{$\begin{array}{c}\text { COCP group }(n=30) \\
\text { Mean }(S D)\end{array}$} & \multicolumn{4}{|c|}{$\begin{array}{c}\text { Placebo group }(n=30) \\
\text { Mean }(S D)\end{array}$} & \multirow[t]{2}{*}{$\boldsymbol{P}^{*}$} & \multirow[t]{2}{*}{$\boldsymbol{P}^{*}$} \\
\hline & Baseline & 3 Months & MD & $\boldsymbol{P}^{*}$ & Baseline & 3 Months & MD & $\boldsymbol{P}^{*}$ & Baseline & 3 months & MD & $\boldsymbol{P}^{*}$ & & \\
\hline Physical health & $\begin{array}{c}21.56 \pm \\
3.4\end{array}$ & $\begin{array}{c}24.44 \pm \\
4.26\end{array}$ & $\begin{array}{c}2.88 \pm \\
0.7\end{array}$ & 0.329 & $\begin{array}{c}20.56 \pm \\
3.01\end{array}$ & $\begin{array}{c}25.33 \\
\pm 5.7\end{array}$ & $\begin{array}{l}4.77 \pm \\
2.03\end{array}$ & 0.07 & $\begin{array}{c}19.85 \pm \\
2.87\end{array}$ & $\begin{array}{c}22.20 \pm \\
7.1\end{array}$ & $\begin{array}{c}2.35 \pm \\
1.9\end{array}$ & 0.102 & 0.87 & 0.38 \\
\hline Psychological health & $\begin{array}{c}17.52 \pm \\
2.242\end{array}$ & $\begin{array}{c}20.56 \pm \\
3.262\end{array}$ & $\begin{array}{c}3.04 \pm \\
0.9\end{array}$ & 0.91 & $\begin{array}{c}18.53 \pm \\
2.04\end{array}$ & $\begin{array}{c}21.74 \pm \\
2.982\end{array}$ & $\begin{array}{c}3.18 \pm \\
1.09\end{array}$ & 0.817 & $\begin{array}{c}18.30 \pm \\
2.20\end{array}$ & $\begin{array}{c}19.05 \pm \\
5.3\end{array}$ & $\begin{array}{c}0.75 \pm \\
0.8\end{array}$ & 0.43 & 0.41 & 0.19 \\
\hline Social relationships & $\begin{array}{c}8.93 \pm \\
1.99\end{array}$ & $\begin{array}{c}10.15 \pm \\
2.179\end{array}$ & $\begin{array}{c}1.22 \pm \\
0.1\end{array}$ & 0.15 & $\begin{array}{l}8.9 \pm \\
1.786\end{array}$ & $\begin{array}{c}10.89 \pm \\
2.118\end{array}$ & $\begin{array}{c}1.93 \pm \\
0.5\end{array}$ & 0.08 & $\begin{array}{l}10.30 \\
\pm 1.21\end{array}$ & $\begin{array}{c}10.10 \pm \\
1.4\end{array}$ & $\begin{array}{c}-0.2 \pm \\
0.4\end{array}$ & 0.65 & 0.1 & 0.27 \\
\hline Environmental health & $\begin{array}{c}21.44 \pm \\
3.76\end{array}$ & $\begin{array}{c}25.85 \pm \\
2.89\end{array}$ & $\begin{array}{c}4.41 \pm \\
2.3\end{array}$ & 0.76 & $\begin{array}{c}21.93 \pm \\
2.97\end{array}$ & $\begin{array}{c}27.44 \pm \\
3.42\end{array}$ & $\begin{array}{c}5.51 \pm \\
1.2\end{array}$ & 0.322 & $\begin{array}{c}20.40 \pm \\
2.3\end{array}$ & $\begin{array}{c}23.30 \pm \\
2.1\end{array}$ & $\begin{array}{c}2.9 \pm \\
3.09\end{array}$ & 0.171 & 0.65 & 0.51 \\
\hline Total point & $\begin{array}{c}69.45 \pm \\
18\end{array}$ & $81 \pm 12$ & $\begin{array}{c}11.55 \pm \\
3.5\end{array}$ & 0.976 & $\begin{array}{c}69.55 \pm \\
21.9\end{array}$ & $\begin{array}{c}85.4 \pm \\
19.9\end{array}$ & $\begin{array}{c}15.85 \pm \\
5.9\end{array}$ & 0.038 & $\begin{array}{c}68.85 \pm \\
38.7\end{array}$ & $\begin{array}{l}73.65 \pm \\
17.3\end{array}$ & $\begin{array}{c}5.8 \pm \\
1.9\end{array}$ & 0.69 & 0.31 & 0.003 \\
\hline
\end{tabular}

MD; mean differences; SD, standard deviation; COCP, Combined oral contraceptive pill.

*Comparison of three groups after intervention in 3 months by ANOVA. Comparison of the mean difference between three groups by ANOVA.

Table 4. Potential Effects of Three Interventions After 3 Months

\begin{tabular}{|c|c|c|c|c|c|}
\hline Variables & & $\begin{array}{c}\text { Dinogest group }(n=30) \\
n(\%)\end{array}$ & $\begin{array}{c}\text { COCP group }(n=30) \\
n(\%)\end{array}$ & $\begin{array}{c}\text { Placebo group }(n=30) \\
n(\%)\end{array}$ & ${ }^{*} \boldsymbol{P}$ Value \\
\hline \multirow{2}{*}{ Spotting, bleeding } & Yes & 7 (16.7) & $6(11.1)$ & $4(7)$ & \multirow{2}{*}{0.13} \\
\hline & No & $23(83.3)$ & 24 (88.9) & $26(93)$ & \\
\hline \multirow{2}{*}{$\begin{array}{l}\text { Hair loss, headache, } \\
\text { nausea, hot flashes }\end{array}$} & Yes & $10(27.8)$ & $6(16.7)$ & $4(7)$ & \multirow{2}{*}{0.57} \\
\hline & No & $16(72.2)$ & $24(83.3)$ & $26(93)$ & \\
\hline \multirow{2}{*}{ Backache } & Yes & $4(7)$ & 0 & $5(8.3)$ & \multirow{2}{*}{0.63} \\
\hline & No & $26(93)$ & $30(100)$ & $25(91.7)$ & \\
\hline \multirow{2}{*}{ Hand numbness } & Yes & $1(2.8)$ & $6(11.1)$ & $4(7)$ & \multirow{2}{*}{0.91} \\
\hline & No & $29(97.2)$ & 24 (88.9) & $26(93)$ & \\
\hline \multirow{2}{*}{ Skin dryness } & Yes & $1(2.8)$ & $1(2.8)$ & $5(13.9)$ & \multirow{2}{*}{0.81} \\
\hline & No & $29(97.2)$ & $29(97.2)$ & $25(86.1)$ & \\
\hline
\end{tabular}

\footnotetext{
${ }^{*}$ Fisher's exact test
} 
and OCPs in women with endometriosis confirmed by surgery and observed the following effects: dysmenorrhea and pelvic pain were clearly reduced in the two groups of intervention, but there was no significant difference between the two intervention groups. We found that $41.7 \%$ and $25 \%$ of patients reported improvement in pain following dienogest and OCPs. Dienogest and OCPs improve women's QOL. However, there is no superiority between the two intervention groups in ameliorating the QOL of women. Drug-related side effects were generally tolerable and the rate of discontinuation was low $(2.8 \%)$ in both intervention groups.

The findings of the present study are consistent with previous reports suggesting that dienogest $\mathrm{t}^{13,21,22}$ and OCPs are effective in reducing pain associated with

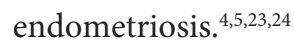

Combined estrogen-progestin oral contraceptives (COCs) have been the first line of treatment for endometriosis for decades, although there has been insufficient evidence for their efficacy. ${ }^{16}$

Studies have shown that compared to placebo, OCPs are effective in reducing dysmenorrhea, pelvic pain, and dyspareunia. ${ }^{12,13,25}$ Although some studies have supported the positive effect of OCPs in reducing pain associated with endometriosis, a meta-analysis study reported that the quality of studies was low and researchers suggested that higher-quality studies should be performed to better clarify the role of OCPs compared to other treatment in women with endometriosis. ${ }^{23}$

In line with our findings, the study by Caruso et al showed that dienogest for three months resulted in a slight improvement in pelvic pain, dysmenorrhea, and dyspareunia. ${ }^{22}$ Proponents of dienogest treatment believe that since dienogest contains no estrogen, it can be a good candidate for inhibiting the growth of endometriosis lesions and reducing the pain caused by endometriosis. ${ }^{21,25}$

According to the present study, there was no difference between dienogest and OCPs in reducing pain associated with endometriosis in the three months after surgery. To date, few studies have compared the effectiveness of dienogest and OCPs in reducing pain in women with endometriosis.

Because the mechanism of action of dienogest is unknown, it is hypothesized that dienogest intervention may suppress pathways regulated by the extracellular signal, control mammalian rapamycin, induce autophagy, and promote endometrial cell apoptosis. ${ }^{12}$ It is also possible that dienogest may increase the progesterone receptor isoform relative to $\mathrm{B} / \mathrm{A}$, thereby increasing the response to progestin treatment in endometrial tissue. ${ }^{13}$ Casper et al suggested that Progestin-only drugs may be a better intervention for the endometrioses than estrogenprogestin contraceptive pills. ${ }^{15}$

The main aim of this study was to compare the impact of dienogest and contraceptive pills in reducing pain associated with endometriosis in the three months after surgery, and according to our study, there was no difference in the effectiveness of these two drugs in reducing pain associated with endometriosis. In the study by Brown et al, no difference was reported between OCPs and other treatments, and researchers suggested that more studies are needed to evaluate the superiority of OCPs to other treatments. ${ }^{1}$ A review of the literature found that, unfortunately, no study has ever compared the effectiveness of dienogest and OCPs in reducing pain associated with endometriosis. Therefore, it is recommended that clinical trials should be designed and performed on these two treatments to confirm the findings of the present study.

In the present study, although dienogest and OCPs led to a slight improvement in the QOL of women with endometriosis, there was no statistically significant difference between the two intervention groups. Researchers believe that the use of hormonal drugs can improve the QOL by reducing dysmenorrhea, dyspareunia, and pelvic pain. Also, taking hormonal medications for three months usually leads to changes in the physical aspects and not the mental aspects of the QOL. ${ }^{26}$ Studies have shown that dienogest consumption for three months led to a slight improvement in women's QOL. ${ }^{26-28}$

However, despite the positive evidence for the effect of OCPs on the QOL of women with endometriosis, the quality of studies in this area has been low. In addition, based on the previous studies, it is not possible to draw a conclusion about the relative superiority of OCPs over other treatments in improving the QOL. ${ }^{23}$ In the present study, the side effects of the drugs were reported very low, and in only two patients, these side effects led to discontinuation of the treatment. Along with the results of the present study, studies have shown that the use of dienogest and OCPs is safe in women with endometriosis..$^{29,30}$ Even long-term use of these drugs has been reported to be safe in studies., ${ }^{30,31}$

To the best of our knowledge, the present study is the first randomized, double-blind, placebo-controlled trial on the comparative effect of dienogest and OCPs on pain and quality life in women with endometriosis. Our data are in agreement with previous reports ${ }^{31,32}$ in that dienogest and OCPs were effective in reducing endometriosis-associated pain. Usually, the first 3 months of consumption of a drug are connoted by objective and subjective adjustments and adaptation to its effectiveness. However, to confirm this finding, more longitudinal studies are necessary.

The design of this study is one of the strengths; randomization was performed using a computergenerated table of random numbers. In addition, the analyzer was blind about the period of intervention, which reduces the likelihood of bias in the primary and secondary outcomes. The current study has its limitations. First, much of the data on important clinical outcomes was missing in some patients. Therefore, to overcome this limitation, all patient data were used based on the 
principle of ITT. Another restriction in the present study was lack of subgrouping based on the stage of the disease or the age of the patients, which could affect the outcome of the study. Another limitation of this study is the shortterm follow-up, necessitating more researches to evaluate the effectiveness of long-term treatment with Dienogest and OCPs in women with endometriosis.

\section{Authors' Contribution}

AM conceived of the presented idea, help supervise the project. GN wrote the manuscript with support from AM and SR, carried out the experiment. SR performed the measurement, were involved in planning and supervised. ME processed the experimental data, drafted the manuscript, designed the figures and verified the analytical methods.

\section{Conflict of Interest Disclosures}

The authors declare that they have no conflict of interest.

\section{Ethical Statement}

In all stages of this study, the principles of the Helsinki Declaration (Ethical Principles for Medical Research, including Humanities) and the Ethics Committee of the University of Iran have been observed. This study was confirmed approved by the Ethics Committee of Iran University of Medical Sciences (IR. IUMS.FMD.REC.1398.128), and was enrolled in the Iranian Clinical Trial Registration List (https://www.irct.ir/trial/43070; identifier: IRCT20191011045063N1). The purposes of the trial were explained to the women being tried at the hearing, and their informed written consent was obtained. Participants were allowed to leave the study at any stage. All personal information was treated confidentially and was only reported collectively.

\section{Funding}

This study was funded by Iran University of Medical Sciences.

\section{Acknowledgements}

We would like to express our special thanks to Iran University of Medical Sciences for the technical support of this research, and we would also like to thank all the women who kindly accepted to participate in this study.

\section{References}

1. Eisenberg VH, Weil C, Chodick G, Shalev V. Epidemiology of endometriosis: a large population-based database study from a healthcare provider with 2 million members. BJOG. 2018;125(1):55-62. doi: 10.1111/1471-0528.14711.

2. Kong S, Zhang YH, Liu CF, Tsui I, Guo Y, Ai BB, et al. The complementary and alternative medicine for endometriosis: a review of utilization and mechanism. Evid Based Complement Alternat Med. 2014;2014:146383. doi: 10.1155/2014/146383.

3. Buggio L, Barbara G, Facchin F, Frattaruolo MP, Aimi G, Berlanda N. Self-management and psychologicalsexological interventions in patients with endometriosis: strategies, outcomes, and integration into clinical care. Int J Womens Health. 2017;9:281-93. doi: 10.2147/ijwh.

\section{s119724.}

4. Culley L, Law C, Hudson N, Denny E, Mitchell H, Baumgarten $\mathrm{M}$, et al. The social and psychological impact of endometriosis on women's lives: a critical narrative review. Hum Reprod Update. 2013;19(6):625-39. doi: 10.1093/humupd/dmt027.

5. Deguara CS, Pepas L, Davis C. Does minimally invasive surgery for endometriosis improve pelvic symptoms and quality of life? Curr Opin Obstet Gynecol. 2012;24(4):2414. doi: 10.1097/GCO.0b013e328355626f.

6. Nezhat C, Vang N, Tanaka PP, Nezhat C. Optimal management of endometriosis and pain. Obstet Gynecol. 2019;134(4):834-9. doi: 10.1097/aog.0000000000003461.

7. Pundir J, Omanwa K, Kovoor E, Pundir V, Lancaster G, Barton-Smith P. Laparoscopic excision versus ablation for endometriosis-associated pain: an updated systematic review and meta-analysis. J Minim Invasive Gynecol. 2017;24(5):747-56. doi: 10.1016/j.jmig.2017.04.008.

8. Weisberg E, Fraser IS. Contraception and endometriosis: challenges, efficacy, and therapeutic importance. Open Access J Contracept. 2015;6:105-15. doi: 10.2147/oajc. s56400.

9. Mira TA, Giraldo PC, Yela DA, Benetti-Pinto CL. Effectiveness of complementary pain treatment for women with deep endometriosis through Transcutaneous Electrical Nerve Stimulation (TENS): randomized controlled trial. Eur J Obstet Gynecol Reprod Biol. 2015;194:1-6. doi: 10.1016/j.ejogrb.2015.07.009.

10. Chapron C, Souza C, Borghese B, Lafay-Pillet MC, Santulli $\mathrm{P}$, Bijaoui G, et al. Oral contraceptives and endometriosis: the past use of oral contraceptives for treating severe primary dysmenorrhea is associated with endometriosis, especially deep infiltrating endometriosis. Hum Reprod. 2011;26(8):2028-35. doi: 10.1093/humrep/der156.

11. Brown J, Crawford TJ, Datta S, Prentice A. Oral contraceptives for pain associated with endometriosis. Cochrane Database Syst Rev. 2018;5(5):CD001019. doi: 10.1002/14651858.CD001019.pub3.

12. Römer T. Long-term treatment of endometriosis with dienogest: retrospective analysis of efficacy and safety in clinical practice. Arch Gynecol Obstet. 2018;298(4):747-53. doi: 10.1007/s00404-018-4864-8.

13. Schindler AE. Dienogest in long-term treatment of endometriosis. Int J Womens Health. 2011;3:175-84. doi: 10.2147/ijwh.s5633.

14. Takagi H, Sakamoto J, Sasagawa T. Long-term treatment of endometriosis with dienogest for up to five years. Clin Exp Obstet Gynecol. 2019;46(3):398-402. doi: 10.12891/ ceog4720.2019.

15. Casper RF. Progestin-only pills may be a better first-line treatment for endometriosis than combined estrogenprogestin contraceptive pills. Fertil Steril. 2017;107(3):5336. doi: 10.1016/j.fertnstert.2017.01.003.

16. American College of Obstetricians and Gynecologists. Practice bulletin no. 114: management of endometriosis. Obstet Gynecol. 2010;116(1):223-36. doi: 10.1097/ AOG.0b013e3181e8b073. 
17. Dunselman GA, Vermeulen N, Becker C, CalhazJorge C, D'Hooghe T, De Bie B, et al. ESHRE guideline: management of women with endometriosis. Hum Reprod. 2014;29(3):400-12. doi: 10.1093/humrep/det457.

18. Practice Committee of the American Society for Reproductive Medicine. Treatment of pelvic pain associated with endometriosis: a committee opinion. Fertil Steril. 2014;101(4):927-35. doi: 10.1016/j.fertnstert.2014.02.012.

19. Zhong B. How to calculate sample size in randomized controlled trial? J Thorac Dis. 2009;1(1):51-4.

20. Vercellini P, Crosignani P, Somigliana E, Viganò P, Frattaruolo MP, Fedele L. 'Waiting for Godot': a commonsense approach to the medical treatment of endometriosis. Hum Reprod. 2011;26(1):3-13. doi: 10.1093/humrep/deq302.

21. Harada T, Momoeda M, Taketani Y, Aso T, Fukunaga $\mathrm{M}$, Hagino $\mathrm{H}$, et al. Dienogest is as effective as intranasal buserelin acetate for the relief of pain symptoms associated with endometriosis--a randomized, double-blind, multicenter, controlled trial. Fertil Steril. 2009;91(3):67581. doi: 10.1016/j.fertnstert.2007.12.080.

22. Strowitzki T, Faustmann T, Gerlinger C, Seitz C. Dienogest in the treatment of endometriosis-associated pelvic pain: a 12-week, randomized, double-blind, placebo-controlled study. Eur J Obstet Gynecol Reprod Biol. 2010;151(2):1938. doi: 10.1016/j.ejogrb.2010.04.002.

23. Jensen JT, Schlaff W, Gordon K. Use of combined hormonal contraceptives for the treatment of endometriosisrelated pain: a systematic review of the evidence. Fertil Steril. 2018;110(1):137-52.e1. doi: 10.1016/j. fertnstert.2018.03.012.

24. Proctor ML, Roberts H, Farquhar CM. Combined oral contraceptive pill (OCP) as treatment for primary dysmenorrhoea. Cochrane Database Syst Rev. 2001(4):CD002120. doi: 10.1002/14651858.cd002120.

25. Strowitzki T, Marr J, Gerlinger C, Faustmann T, Seitz C. Dienogest is as effective as leuprolide acetate in treating the painful symptoms of endometriosis: a 24-week, randomized, multicentre, open-label trial. Hum Reprod. 2010;25(3):633-41. doi: 10.1093/humrep/dep469.

26. Caruso S, Iraci M, Cianci S, Vitale SG, Fava V, Cianci A. Effects of long-term treatment with dienogest on the quality of life and sexual function of women affected by endometriosis-associated pelvic pain. J Pain Res. 2019;12:2371-8. doi: 10.2147/jpr.s207599.

27. Davis L, Kennedy SS, Moore J, Prentice A. Oral contraceptives for pain associated with endometriosis. Cochrane Database Syst Rev. 2007(3):CD001019. doi: 10.1002/14651858.CD001019.pub2.

28. Grandi G, Barra F, Ferrero S, Sileo FG, Bertucci E, Napolitano A, et al. Hormonal contraception in women with endometriosis: a systematic review. Eur J Contracept Reprod Health Care. 2019;24(1):61-70. doi: 10.1080/13625187.2018.1550576.

29. Park SY, Kim SH, Chae HD, Kim CH, Kang BM. Efficacy and safety of dienogest in patients with endometriosis: a single-center observational study over 12 months. Clin Exp Reprod Med. 2016;43(4):215-20. doi: 10.5653/ cerm.2016.43.4.215.

30. Petraglia F, Hornung D, Seitz C, Faustmann T, Gerlinger C, Luisi S, et al. Reduced pelvic pain in women with endometriosis: efficacy of long-term dienogest treatment. Arch Gynecol Obstet. 2012;285(1):167-73. doi: 10.1007/ s00404-011-1941-7.

31. Sugimoto K, Nagata C, Hayashi H, Yanagida S, Okamoto A. Use of dienogest over 53 weeks for the treatment of endometriosis. J Obstet Gynaecol Res. 2015;41(12):1921-6. doi: 10.1111/jog.12811.

32. Petraglia F, Hornung D, Seitz C, Faustmann T, Gerlinger C, Luisi S, et al. Reduced pelvic pain in women with endometriosis: efficacy of long-term dienogest treatment. Arch Gynecol Obstet. 2012;285(1):167-73. doi: 10.1007/ s00404-011-1941-7. 